\title{
DORSAL ONLAY BUCCAL MUCOSAL GRAFT URETHROPLASTY FOR BULBAR URETHRAL STRICTURE- EXPERIENCE OF 20 CASES
}

\author{
AL-ASAD H ${ }^{1}$, BHUIYAN AKMM ${ }^{2}$, ISLAM MN ${ }^{3}$, KARMAKER U $^{4}$, CHOWDHURY SA $^{5}$, SAHA PK ${ }^{6}$, \\ HOSSAIN AKMS ${ }^{7}$, ALAM SMM ${ }^{8}$
}

\begin{abstract}
Objective: To assess the success of buccal mucosal graft (BMG) urethroplasty by the dorsal onlay technique in bulbar urethral stricture.

Materials and Methods: From July 2008 to June 2010, twenty patients with anterior urethral strictures were managed by dorsal onlay BMG urethroplasty. After voiding trial, they were followed up at 3 weeks and 3 months with history, physical examination, uroflowmetry and retrograde urethrogram (RGU) if required. Patients were further followed-up at 3 months interval with uroflowmetry and retrograde urethrogram (RGU) if required. Successful outcome was defined as normal voiding with no surgical intervention after catheter removal.
\end{abstract}

Results: Mean stricture length was $3.5 \pm 0.8 \mathrm{~cm}$ and mean follow up was 12 months (range 6 to 24 months). Two patients were found to develop stricture at anastomotic site, during followup and required optical internal urethrotomy and was considered as failure. One patient developed wound infection which resolved after regular dressing. Success rate was 90\%.

Conclusion: Dorsal onlay BMG urethroplasty is a simple technique with good surgical outcome.

Key words: Urethral stricture, Buccal mucosal graft (BMG), Retrograde urethrogram (RGU), Voiding cystourethrogram (VCUG), Optical internal urethrotomy (OIU).

J Dhaka Med Coll. 2017; 26(1) : 8-11

\section{Introduction}

Urethral stricture is fibrotic narrowing of urethral lumen; fibrosis usually extends into the surrounding corpus spongiosum causing spongiofibrosis. Urethral reconstruction remains a challenge in modern urology practice. The treatment of urethral strictures varies according to location, length, depth and density of the stricture. Optical internal urethrotomy (OIU) may be useful for short annular strictures, but this procedure is associated to a very high recurrence rate. ${ }^{1}$ Urethral reconstruction with excision of the strictured segment and end-to-end anastomosis is successful in more than 95\% of patients with a stricture of up to $2 \mathrm{~cm}$ in length. ${ }^{2}$ Patients with long strictures $(>2 \mathrm{~cm}$ in length) are not suitable for end-to-end urethroplasty due to the risk of postoperative chordee formation. ${ }^{3}$ Substitution urethroplasty is ideal for the management of long anterior urethral strictures. The ideal material for substitution urethroplasty remains controversial. ${ }^{4}$ Urethral substitution has long been accomplished by using genital skin flaps, grafts of genital or extragenital tissue. ${ }^{5}$ Currently, buccal mucosa graft substitution urethroplasty is the most preferred option for long bulbar urethral strictures. Buccal mucosa offers the advantages of being accustomed to a wet environment, having good vascularity, hair

1. Dr. Hafiz Al-Asad, Registrar, Department of Urology, Dhaka Medical College \& Hospital, Dhaka.

2. Dr. A.K.M. Musa Bhuiyan, Assistant Professor, Department of Urology, Dhaka Medical College \& Hospital, Dhaka

3. Dr. Md. Nazmul Islam, Residential Surgeon, Department of Urology, Dhaka Medical College \& Hospital, Dhaka.

4. Dr. Uttam Karmaker, Assistant Professor, Department of Urology, Dhaka Medical College \& Hospital, Dhaka.

5. Dr. Md. Shafiqul Alam Chowdhury, Associate Professor, Department of Urology, Dhaka Medical College \& Hospital, Dhaka.

6. Dr. Prodyut Kumar Saha, Associate Professor, Department of Urology, Dhaka Medical College \& Hospital, Dhaka.

7. Dr. A.K.M. Shahadat Hossain, Associate Professor, Department of Urology, Dhaka Medical College \& Hospital, Dhaka.

8. Prof. S.M. Mahbub Alam, Professor \& Head, Department of Urology, Dhaka Medical College \& Hospital, Dhaka. Correspondance: Dr. Hafiz Al-Asad, Registrar, Department of Urology, Dhaka Medical College \& Hospital, Dhaka. Received: 01 January 2017

Accepted: 01 March 2017 
less, easy to harvest, thick epithelium making it easy to handle and less chance of graft contracture, having a thin lamina propria allowing early inosculation, reduced rate of pseudo-diverticulum formation. ${ }^{4}$ Weather to place the graft dorsally, ventrally or laterally is still controversial. Dorsal onlay graft procedure provides the advantages of better mechanical support by the corporal bodies with fewer incidences of sacculation and fistula formation but this approach may damage erectile function and the bulbar arteries when the dissection from the corpora needs to be very proximal. ${ }^{6}$ In our study, we describe our experience with dorsal buccal mucosal graft (BMG) urethroplasty for long segment bulbar urethral stricture.

\section{Materials and Methods}

From July 2008 to June 2010, twenty patients with long bulbar urethral stricture were managed by single stage urethroplasty with a dorsalonlay patch BMG. Each patient was evaluated with history, physical examination, uroflowmetry, imaging study with retrograde urethrogram (RGU) and voiding cystourethrogram (VCUG) and other routine investigations required for anaesthetic fitness. All the patients were selected purposively according to the selection criteria that were, patients having primary and recurrent stricture of anterior urethra involving the bulbar urethra, stricture length $2 \mathrm{~cm}$ to $6 \mathrm{~cm}$, patients with significant lower urinary tract symptoms and patient given consent for operation and record for study purpose. Stricture involving posterior and distal penile urethra and with oral pathology were excluded. Ethical committee's approval was taken to perform the study. Operation was performed under general anesthesia with naso-tracheal intubation and the patient was put in exaggerated lithotomy position. Operation was done in a 2 -team approach-one team engaged in urethral procedure and other team in harvesting the buccal mucosa. Through a midline perineal incision, the bulbo-cavernosus muscle was divided exposing the corpus spongiosum of the anterior urethra. Then the bulbar urethra was easily dissected from corpora cavernosa. Then the strictured segment of the urethra was identified. The other team then harvested the buccal mucosal graft of adequate length, from the inner cheek area below the Stensen's duct without injuring it. Lignocaine $(2 \%)$ with adrenaline $(1: 200000)$ was injected into the edges of the desired graft length before harvesting to get better hemostasis. Graft donor site is closed with continuous 4-0 chromic catgut sutures to achieve good hemostasis. The graft was then defatted and tailored to its proper size. The dissected urethra was rotated $180^{\circ}$. The dorsal surface of the strictured segment was exposed and opened vertically extending the incision for about $1 \mathrm{~cm}$ both proximally and distally into the normal urethral lumen. The proximal and distal urethral lumens of the urethra were calibrated. The right margin of the graft was sutured with the urethral margin using 5-0 polyglactin suture. Foley catheter was inserted through the urethra into the urinary bladder. Then the urethra was rotated back to its original position and left margin of the urethral mucosa was sutured to the graft using 5-0 polyglactin continuous suture. Few interrupted stitches were given to fix the graft with the corpora cavernosa along the midline dorsally. Suprapubic catheterization was done in all patients. The patient was maintained on antibiotics until the catheter was removed. Three weeks after the operation the urethral catheter was removed if patient could void well then the suprapubic catheter was removed on the next day. All the patients were advised to visit at outpatient door on 3 weeks and on 3 months for follow up. During follow up patient's history, physical examination, uroflowmetry were done. If uroflowmetry showed significant obstruction then retrograde urethrogram (RGU) and voiding cystourethrogram (VCUG) was done. A successful outcome was defined as normal voiding with no need of any kind of surgical inervention. Patients were further followed-up at 3 months interval with uroflowmetry and RGU and VCUG if required.

\section{Results}

Total 20 patients (mean age $42.6 \pm 10.2$ years) were underwent BMG urethroplasty by dorsal onlay graft between July 2008 to June 2010. Most of the patients presented with poor flow of urine, some presented with per-urethral 
discharge and few of them presented with acute retention of urine. Mean stricture length was $3.5 \pm 0.8 \mathrm{~cm}$. Among the patients the cause of stricture were 11 inflammatory, 7 idiopathic and 2 were iatrogenic that were catheter induced trauma. Before surgery mean peak urinary flow rate was $8.9 \pm 2.5 \mathrm{ml} / \mathrm{sec}$. Mean operative time was $110 \mathrm{~min}$ (range 100 to 165 min) and mean follow- up 12 months (range 6 to 24 months). All patients required peroperative blood transfusion but no patients required it postoperatively. Nineteen patients were discharged on $4^{\text {th }}$ post-operative day, only one patient how developed wound infection was managed successfully with change in antibiotics as per wound swab culture sensitivity test and regular dressing and was discharged on $14^{\text {th }}$ post-operative. On urethral catheter removal of that patient he could void well and needed no intervention. On follow up peak urinary flow rate improved significantly. At 3 weeks and at 3 months the mean peak urinary flow rate was $18.9 \pm 5.1$ and $24.0 \pm 8.9$ $\mathrm{ml} / \mathrm{sec}$ respectively. Two patients developed stricture at proximal anastomotic site which was addressed during follow up and required optical internal urethrotomy and was considered as failure. In our series the mean follow up was 12 months (range 6 to 24 months).

\section{Discussion}

Urethral strictures were documented in ancient literature dating from Greek and Egyptian period. Continuous attempts are made in different parts of the world in different centers to find out an ideal method of treatment according to the merit of individual type of stricture. Significant progress made over the last 30 years. ${ }^{7}$ Long anterior urethral stricture ( $>2 \mathrm{~cm}$ long) should be treated with substitution urethroplasty to avoid postoperative chordee formation. ${ }^{3}$ Substitution urethroplasty may be a patch graft or tube graft..$^{8} 9$ Free skin grafts used as patch or tube graft in substitution urethroplasty are associated with complications like graft shrinkage, diverticulum formation and recurrent stricture, although results of patch grafts are better than tube grafts ${ }^{10,11,12}$ Humby was the first to use buccal mucosa for urethral reconstruction in a series of single stage hypospadias repair. However, BMG urethroplasty has emerged as a popular technique in 1990s. Whether to place the graft dorsally, ventrally or laterally is still controversial now. Ventral onlay graft is more prone to fistula formation, sacculation and diverticula formation leading to urinary stasis and ejaculatory dysfunction. ${ }^{4}$ On the other hand, dorsal onlay graft procedure for the anterior urethral stricture provides the advantages of better mechanical support by the corporal bodies for the graft's better take up, with less incidence of sacculation and fistula formation. ${ }^{6,13}$ It has been reported that dorsally placed graft can do better because of better mechanical support for the graft and a richer vascular bed from the underlying corporal bodies. $^{8}$ In different series, dorsal onlay BMG urethroplasty has shown a success rate from $87.5 \%$ to $100 \%$ with a follow-up ranging from 22 to 41 months. ${ }^{14,15}$ Recently, Barbagli et al. published a retrospective study of 50 cases with bulbar urethral stricture where buccal mucosal graft urethroplasty were done. ${ }^{16}$ In their study, grafts were placed as ventral, dorsal and lateral onlay in 17, 27 and 6 patients respectively. After a meanfollow-up of 42 months, placement of graft into ventral, dorsal or lateral surface of the bulbar urethra showed the similar success rate. In our series of 20 cases, only two patients developed re-stricture at proximal atanastomotic sites. One patient developed stricture within 3 months of operation and another one showed evidence of stricture on RGU after 6 months of operation. These two $(10 \%)$ were considered as failure, because these patients developing stricture after BMG urethroplasty and needed surgical intervention that is optical internal urethrotomy. In our series the success rate was $90 \%$ which was nearly similar to the other studies. ${ }^{14,} 15$ Our mean follow-up was long enough 12 months (range 6 to 24 months).

\section{Conclusion}

In our study, it has been shown that dorsal BMG urethroplasty is a reliable and satisfactoryprocedure to manage long bulbar urethral strictureswith minimum complications. Harvesting the graft is simple. Few cases, considered as failure with stricture 


\section{formation can be managed with optical internal urethrotomy.}

\section{References}

1. Heyns C.F., Steenkamp J.W., DeKock M.L., Whitaker P. Treatment of male urethral strictures: is repeated dilation or internal urethrotomy useful?. J Urol. 1998; 160: 356-8.

2. Webster G.D., Robertson C.N. The vascularized skin island urethroplasty: its role and results in urethral stricture management. J Urol. 1985; 133: 31-3.

3. Gupta N.P., Ansari M.S., Dogra P.N., Tandon S. Dorsal buccal mucosal graft urethroplasty by a ventral sagittal urethrotomy and minimal-access perineal approach for anterior urethral stricture. BJU Int. 2004; 93: 1287-90.

4. Bhargava S., Chapple C.R. Buccal mucosal urethroplasty: is it the new gold standard? BJU Int. 2004; 93: 1191-3.

5. Morey A.F. \& McAninch J.W. Techniques of harvesting buccal mucosa for urethral reconstruction. J Urol. 1996; 155: 1696.

6. Iselin C.E. \& Webster G.D. Dorsal onlay graft urethroplasty for repair of bulbar urethral strictures. J Urol. 1999; 161: 815-18.

7. Jordan G.H. and Schlossberg S.M. Surgery of the penis and urethra. In: Wein, A.J., Kavoussi, L.R., Novick, A.C., Partin, A.W., Peter, C.A., eds. Campbell's Urology. $9^{\text {th }}$ ed. Philadelphia: Saunders. 2007; 1023-1097.

8. Barbagli G., Palminteri E., Rizzo M. Dorsal onlay graft urethroplasty using penile skin or buccal mucosa in adult bulbourethral strictures. J Urol. 1998; 160: 1307-9.

9. Brannan W., Ochsner M.G., Fuselier H.A., Goodlet J.S. Free full thickness skin graft urethroplasty for urethral stricture: experience with 66 patients. J Urol. 1976; 115: 677-80.

10. Orandi A. One-stage urethroplasty. Br J Urol. 1968; 40: 717-9.

11. Morey A.F., McAninch J.W. Technique of harvesting buccal mucosa for urethral reconstruction. J Urol. 1996; 155: 1696-7.

12. Venn S.N., Mundy A.R. Early experience with the use of buccal mucosa for substitution urethroplasty. Br J Urol. 1998; 81: 738-40.

13. Barbagli G., Selli C., Tosto A., Palminteri E. Dorsal freegraft urethroplasty. J Urol. 1996; 155: 123-6.

14. Dubey D., Kumar A., Bansal P., Srivastava A., Kapoor R., Mandhani A., et al.: Substitution urethroplasty for anterior urethral strictures: a critical appraisal of various techniques. BJU Int. 2003; 91: 215-8.

15. Pansadoro V., Emiliozzi P., Gaffi M., Scarpone P., DePaula F., Pizzo M. Buccal mucosa urethroplasty in the treatment of bulbar urethral strictures. Urology. 2003; 61: 1008-10.

16. Barbagli G., Palminteri E., Guazzoni G., Montorsi F., Turini D., Lazzeri M. Bulbar urethroplasty using buccal mucosa grafts placed on the ventral, dorsal or lateral surface of the urethra: are results affected by the surgical technique?. J Urol. 2005; 174: 955-7. 